\title{
SOME INEQUALITIES FOR GENERALIZED BELL-TOUCHARD POLYNOMIALS
}

\author{
HAI-Rong YAN, QIAO-Ling Zhang And AI-Min XU
}

Abstract. A unified generalization for the Bell-Touchard polynomials of order $k$ and the $r$-Bell polynomials is established. It is shown that the generating function of the generalized BellTouchard polynomials is logarithmically absolutely monotonic. Applying this result we obtain some inequalities for the generalized Bell-Touchard polynomials. In particular, we obtain the logarithmic convexity of the generalized Bell-Touchard polynomials.

Mathematics subject classification (2010): 11B73, 26A48, 26A51, 33B10.

Keywords and phrases: Bell-Touchard polynomial, inequality, absolutely monotonic, completely monotonic, logarithmic convexity.

\section{REFERENCES}

[1] N. Asai, I. Kubo, H. - H. KuO, Bell numbers, log-concavity, and log-convexity, Acta Appl. Math. 63(1-3) (2000), 79-87.

[2] A. Z. BRODER, The r-Striling numbers, Discrete Math. 49 (1984), 241-259.

[3] L. CARlitz, Weighted Stirling numbers of the first and second kind I, Thd Fibonacci Quarterly 18 (1980), 147-162.

[4] L. CARlitz, Weighted Stirling numbers of the first and second kind II, Thd Fibonacci Quarterly 18 (1980), 242-257.

[5] W. - X. MA, Bilinear equations, Bell polynomials and linear superposition principle, J. Phys. Conf. Ser. 411(1) (2013), Aricle ID: 012021, 11 pages.

[6] W. - X. MA, Bilinear equations and resonant solutions characterized by Bell polynomials, Rep. Math. Phys. 72(1) (2013), 41-56.

[7] W. - X. MA, Trilinear equations, Bell polynomials, and resonant solutions, Front. Math. China 8(5) (2013), 1139-1156.

[8] T. Mansour, M. Schork, Commutation Relations, Normal Ordering and Stirling Numbers, CRC, 2015.

[9] I. MEZŐ, The r-Bell numbers, J. Integer Sequence 14 (2011), Article 11.1.1.

[10] I. MEZŐ, J. L. RAMÍREZ, Divisibility properties of the $r$-Bell numbers and polynomials, J. Number Theory 177 (2017), 136-152.

[11] D. S. Mitrinović, Analytic inequalities, Springer-Verlag, 1970.

[12] D. S. Mitrinović, J. E. PeČARIĆ, On two-place completely monotonic functions, Anzeiger Öster. Akad. Wiss. Math.-Natturwiss. K1. 126 (1989), 85-88.

[13] D. S. Mitrinović, J. E. PeČARIĆ, A. M. Fink, Classical and new inequalities in analysis, Kluwer Academic Publishers, 1993.

[14] J. E. PEČARIĆ, Remarks on some inequalities of A. M. Fink, J. Math. Anal. Appl. 104(2) (1984), $428-431$.

[15] F. QI, Some inequalities for the Bell numbers, Proc. Indian Acad. Sci. Math. Sci. 127(4) (2017), 551564.

[16] F. QI, D. Lim, B. - N. GUO, Explicit formulas and identities for the Bell polynomials and a sequence of polynomials applied to differential equations, Rev. R. Acad. Cienc. Exactas Fís. Nat. Ser. A Mat. RACSAM (2018), in press; Available online at https://doi.org/10.1007/s13398-017-0427-2. 
[17] F. QI, D. - W. NiU, D. Lim, B. - N. GuO, A unified generalization of the Bell numbers and the Touchard polynomials and its properties, ResearchGate Working Paper (2017), available online at https://doi.org/10.13140/RG.2.2.36733.05603.

[18] F. QI, D.-W. NiU, D. Lim, AND B.-N. Guo, Generalizations of the Bell numbers and polynomials and their properties, Preprints 2017, 2017080090, 12 pages; Available online at https://doi.org/10.20944/preprints201708.0090.v1.

[19] R. L. SChilling, R. SOng, Z. VondračEK, Bernstein Functions-Theory and Applications, 2nd ed., de Gruyter Studies in Mathematics 37, Walter de Gruyter, Berlin, Germany, 2012.

[20] H. VAN HAERINGEN, Inequalities for real powers of completely monotonic functions, J. Math. Anal. Appl. 210(1) (1997), 102-113.

[21] D. V. WidDER, The Laplace Transform, Princeton University Press, Princeton, 1946. 